\title{
Modelling and Analysis of Thermomechanical Stress at Connected Areas of Mini-lifting equipment using Three Different Methods
}

\author{
Thi Hai Van Nguyen \\ University of Technology and Education \\ The University of Danang \\ 48 Cao Thang Street, Danang City, Viet Nam \\ Minh -Man Pham* \\ Department of Mechanical Engineering, \\ University of Technology and Education \\ The University of Danang \\ 48 Cao Thang Street, Danang City, Viet Nam
}

\author{
Nguyen Le Van \\ University of Technology and Education \\ The University of Danang \\ 48 Cao Thang Street, Danang City, Viet Nam \\ Nguyen Thai Duong \\ University of Technology and Education \\ The University of Danang \\ 48 Cao Thang Street, Danang City, Viet Nam
}

\begin{abstract}
Mini lifting equipment with permissible load of $150 \mathrm{~kg}$ are used to perform the main functions such as moving, lifting people and things at constructive works or fire protection projects. During lifting, the device is always affected by many factors such as mass, gravity, load, lifting speed, and others. This paper focuses on simulation and analysis of differences in stress distribution at connected joints of this lifting device in life-cycle after working oscillation process. In this paper, three different methods were used, including finite element analysis, method of separation of nodes, and method of using CAD software to simulate and evaluate stress differences at these positions. With permissible working cycle under the assumption based on the rotation speed of the joint position, the result has shown the maximum and smallest value after meshing and analysing during simulation.
\end{abstract}

Keywords-Mini lifting equipment, finite element analysis, separation of nodes, stress distribution, CAD simulation.

\section{INTRODUCTION}

Mini lifting equipment has many types and they are controlled by various forms from mechanic, electric, hydraulic and combined-control. The main purpose of lifting equipment is to meet the lifting of equipment for construction, production, repair and support. Previous studies [1-5] have proposed suggestions for evaluation, survey, calculation, simulation and dynamics experiments of different types of lifting devices. In addition, some recent studies such as [6,7] have focused on safety factors during the transportation and operation $\mathrm{f}$ aerial lifting equipment with the permitted height. In Vietnam, there are many directions of surveying and producing some types of lifting equipment according to large standards to serve the works with very high prices like [8]. Considering the types of control of lifting equipment, in Vietnam, they are mainly designed for mechanical uses or small cylinder hydraulic lifting mechanisms to serve in garages which have a low aperture. With the small-load model being processed and fabricated, our group also conducted simulation and analysis of relevant details in this lifting device. We pay special attention to analysing the stress distribution process at linked points using three different methods. Moreover, moving speed and life cycles after working at these links were also considered to assess the effect of temperature and working cycle over time.

In this paper, we did not assess the effects of destruction at welds, at locations of residual stresses, rust holes or moving places subjected to dynamic loads, most of assessment are all due to the forces, loads, vibrations as previous studies [9] with similar models to consider working time, and temperature environment to deform, fracture or reduce life expectancy. In addition, we focus on calculating stress when the load is eccentric as well as centred. By analysing force at the linked positions through the method of separation of nodes, finite element analysis and CAD simulating software, this research examines at the linked positions whether the mini lifting equipment with $150 \mathrm{~kg}$ load ensures stress resistance during operation.

\section{FINITE ELEMENT ANALYSIS (FEA)}

In mini lifting equipment, there are many related details including external connecting bar, inner push bar, force transmission structure, lifting platform, sliding mechanisms, rolling structure, matching structure, and others. With the finite element method, we consider the link point of the mini lifting device. In the process of stresses analysis using the finite element method, we only consider the bonding points on the $\mathrm{X}, \mathrm{Y}$, and $\mathrm{Z}$ axes of the lifting device in 2D coordinates and using CAD simulation software. With simulation function, force analysis and impact factors depends on internal and external connecting bars and link point details. 


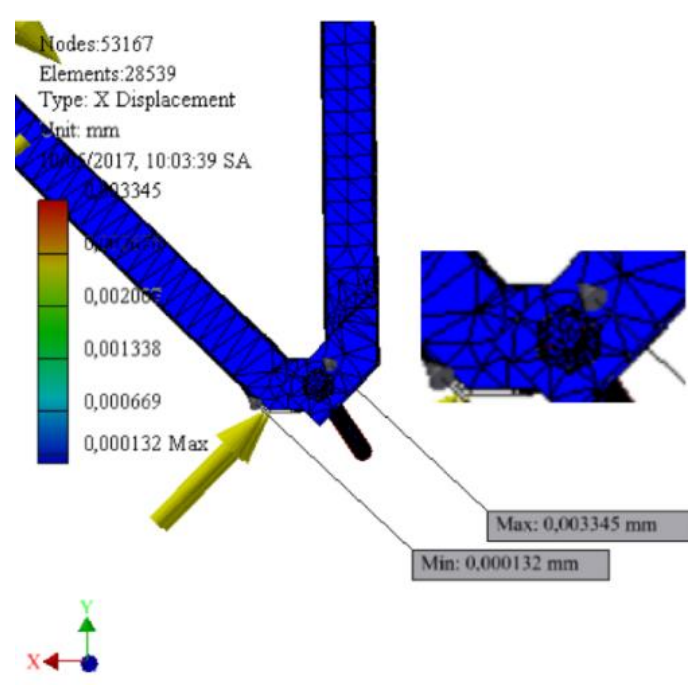

Fig. 1. Number nodes and elements for FEA of $\mathrm{X}$ axe

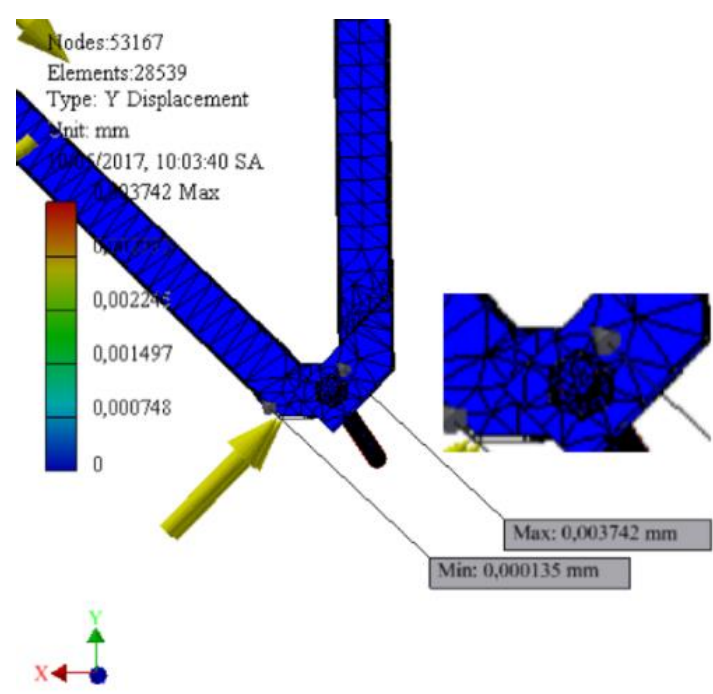

Fig. 2. Number nodes and elements for FEA of Y axe

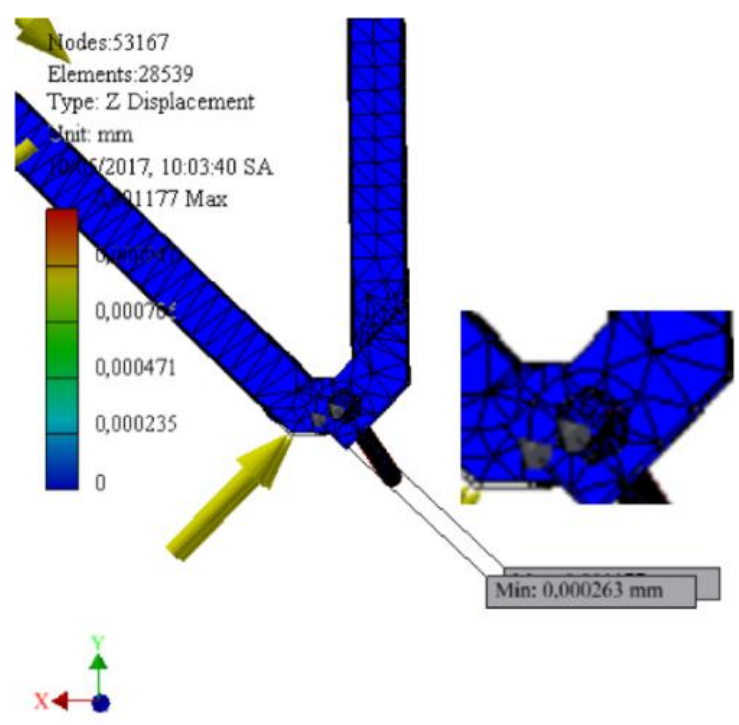

Fig. 3. Number nodes and elements for FEA of $\mathrm{Z}$ axe
The load is distributed on the upper frame where the lifting device and the person with maximum weight are considered $150 \mathrm{~kg}$. Autodesk Inventor software for academic use is freely available for teachers and students and not related to copyright. This software combines extensive functions and tools that are available during the sketch phase, meshing and force analysis simulation as described in previous studies [10,11]. Models are subdivided into structures with 53167 nodes and 28239 elements for all three directions $\mathrm{X}, \mathrm{Y}$, and $\mathrm{Z}$ as Figure 1, 2, and 3. To simulate this structure, we used a computerized mathematical model with i-core 5 configurations, Sony Vio. As can be seen in these figures, all three $\mathrm{X}, \mathrm{Y}$, and $\mathrm{Z}$ directions have different grid distributions and the structure is deformed during the motion without eliminating fluctuations or deviations. In this paper, we did not consider the vibration process and the factors affecting the lifting device except the temperature field in the working cycle with the movement speed. With the mesh characteristics and default dimensions of link points, we simulated with Inventor software and element analysis at the connection location of the lifting device.

The maximum eccentricity occurred as shown in Figure 1 for $\mathrm{X}$ direction, Figure 2 for $\mathrm{Y}$ direction, and Figure 3 for $\mathrm{Z}$ direction. The figure also clearly shows the maximum deflection in the divided grid; the most deviations are also highlighted with Red color. In general, the deflection position in the grids at the $\mathrm{X}, \mathrm{Y}$, and $\mathrm{Z}$ directions is small, and the deviations occurring on steel material structure are evident through the analysis of the internal structure at connecting bars. The previous article of the same author [9] confirmed the maximum deviation of these bars during the calculation as well as the simulation. The previous results also showed that the internal and external deviations differ between bars according to determined directions when holding the load up to $50 \%$.

\section{ANALYZE FORCES BY ADAMS/VIEW}

We use Adam dynamite simulation software to simulate and determine the force on the bars at the assembly points using reference [12]. In this simulation, we also considered the case of eccentric load, which means that the load of 1500 $\mathrm{N}$ is set at an angle and in the case of the load placed in the middle of the upper frame and divided equally for the lifting frame. Lift angle is from 0 to $51^{0}$ corresponding to the lowest and highest position of the lifting frame.

In another study [13], which simulated a bar with a similar structure and material (as shown in Figure 4), there was also great distortion when it was subjected to over load.

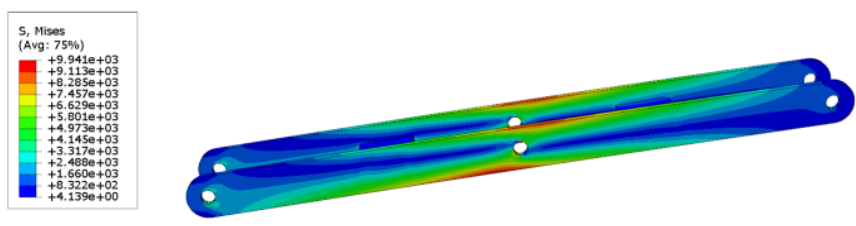

Fig. 4. shows with a stress distribution of the Adams simulation

Similarly, we analysed the mini lifting equipment of 150 $\mathrm{kg}$ and the load on the frame is eccentric with different angles. The modelling process was performed according to the relative position of the frame. 
Simulation time: $0.5 \mathrm{~s}$, Steps: 5000 - Speed of pulling the shaft (when pulling the bottom shaft) $\mathrm{v}=50 \mathrm{~mm} / \mathrm{s}$. Initially, due to the gap exists, when the work starts, there is a collision; so the force is high, but it stabilizes fast as we can see in Figure 5 and Figure 6.

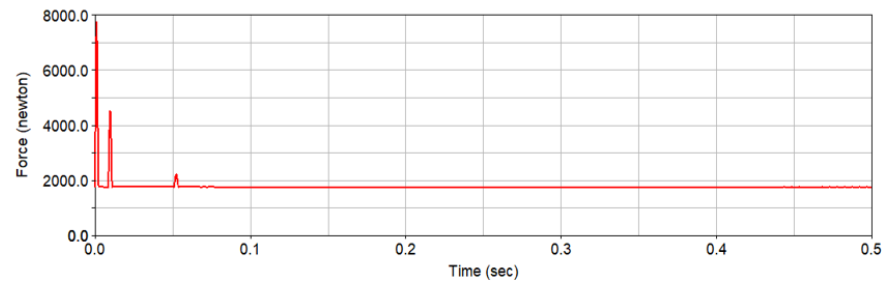

Fig. 5. Axial force inside bar $1($ Fmax $=1777 \mathrm{~N})$

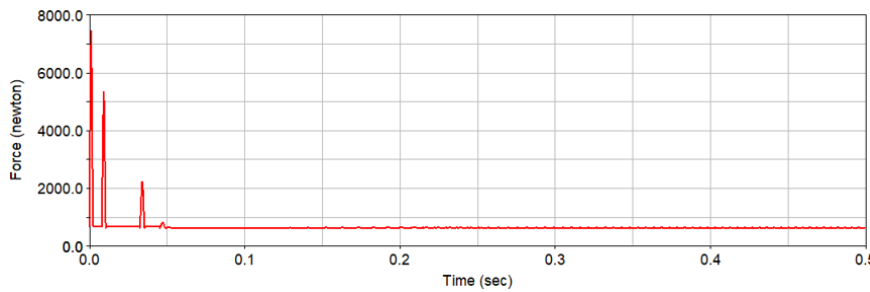

Fig. 6. Axial force inside bar $1(\operatorname{Fmax}=680 \mathrm{~N})$

The results of the ADAMS/View simulations are consistent with those from manual analysis and computation, $1758 \mathrm{~N}$ vs. $1777 \mathrm{~N}$ and $575 \mathrm{~N}$ vs. $680 \mathrm{~N}$. Durability test, in the case of the load placed at an angle (Case 1) and placed in the middle of the upper frame (Case 2).

On the bar 1, 2: $\sigma_{1,2}=\frac{F_{1,2}}{A}=\frac{N_{1,2}}{A}$

TABLE I. THE RESULTS OF DURABILITY TEST USING ADAMS/VIEW

\begin{tabular}{|c|c|c|c|c|c|}
\hline Case & $\mathbf{A}$ & $\mathbf{N}_{1}(\mathbf{N})$ & $\mathbf{N}_{2}(\mathbf{N})$ & $\begin{array}{c}\boldsymbol{\sigma}_{\mathbf{1}} \\
\left(\mathbf{N} / \mathbf{m}_{2}\right)\end{array}$ & $\begin{array}{c}\boldsymbol{\sigma}_{\mathbf{2}} \\
\left(\mathbf{N} / \mathbf{m}_{2}\right)\end{array}$ \\
\hline 1 & $\begin{array}{c}216.16 \\
\mathrm{x} 10^{-6}\end{array}$ & 1777 & 1263 & $8.22 \times 10^{6}$ & $5.84 \times 10^{6}$ \\
\hline 2 & $\begin{array}{c}216.16 \\
\times 10^{-6}\end{array}$ & 680 & 1263 & $3.15 \times 10^{6}$ & $5.84 \times 10^{6}$ \\
\hline
\end{tabular}

In Table I, the results of stress in two cases (1 and 2) of two bars are shown according to Equation 1. The results show that the stress at bar 1 of case 1 is very large, and particularly, case 1 is twice as large as case 2 . However, the stress at bar 2 is the same for both methods (Finite Element method and Adams/View analysis).

\section{METHOD OF SEPARATION OF NODES (MSN)}

The research results of [9] of the same authors showed in detail force analysis steps at different bars and nodes at the link positions of the frame of mini lifting device.

Supposing that in the case of people and things near corner the most, the value $b_{2}=b / 2=400 \mathrm{~mm}, a_{2}=a / 2=300$ $\mathrm{mm}$. By replacing the designed geometry parameters with the maximum lifting capacity $\mathrm{Q}(\mathrm{N})$, we get the maximum value effecting on point B. Similarly, we have established the equilibrium force equations at nodes $\mathrm{D}$ and $\mathrm{E}$.

Where: $\mathrm{N}_{\mathrm{B}}=1375 \mathrm{~N}, \alpha=51^{\circ}$, we define the axial force values on each bar. With $\mathrm{Q}=150 \times 1.2=180 \mathrm{~kg}=1800(\mathrm{~N})$, $\mathrm{G}=100$ and $[\sigma]_{\mathrm{T}}=14 \mathrm{kN} / \mathrm{cm}^{2}=140.10^{6} \mathrm{~N} / \mathrm{m}^{2}$.
The load acting on the positions A, B, C, D is the link of the upper frame with the 4 vertices of the crossbar. In Figure 7, point B will bear the largest load. According to [9].

$$
N_{B}=\frac{G}{4}\left(1+\frac{2 b_{1}}{b}\right)+\frac{Q}{4}\left(1+2 \frac{b_{2}}{b}+2 \frac{a_{2}}{a}\right)
$$

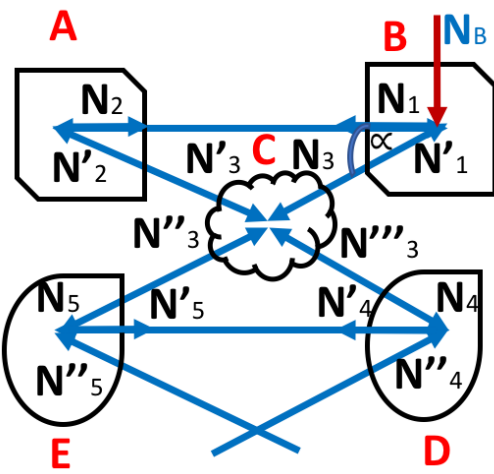

Fig. 7. Force distribution diagram in the case of the load focusing to one side

After calculation, we have: $\mathrm{N}_{1}=\mathrm{N}_{2}=1095.4 \mathrm{~N} ; \mathrm{N}^{\prime}{ }_{1}=\mathrm{N}^{\prime}{ }_{2}$ $=\mathrm{N}_{3}=\mathrm{N}^{\prime}{ }_{3}=\mathrm{N}_{4}=\mathrm{N}_{5}=1758.3 \mathrm{~N} ; \mathrm{N}^{\prime}{ }_{4}=\mathrm{N}^{\prime}{ }_{5}=2190.6 \mathrm{~N}$

The bars in the mini lifting equipment with axial compressive force. Test the compressive strength of the bar [8]: $\sigma=\frac{F}{A} \leq[\sigma]$, With: $[\sigma]_{\mathrm{T}}=14 \mathrm{kN} / \mathrm{cm}^{2}=140 \times 10^{6} \mathrm{~N} / \mathrm{m}^{2}$.

The results in Table II also show that when using case 2, the stresses are relatively similar for both the stress position of the bars and nodes. But in case 1, this value is nearly twice.

TABLE II. THE RESULTS OF DURABILITY TEST FORCE DISTRIBUTION

\begin{tabular}{|c|c|c|c|c|c|}
\hline No. & $\mathbf{A}$ & $\mathbf{N}_{\mathbf{1}}(\mathbf{N})$ & $\mathbf{N}_{\mathbf{2}}(\mathbf{N})$ & $\begin{array}{c}\boldsymbol{\sigma}_{\mathbf{1}} \\
(\mathbf{N} / \mathbf{m} 2)\end{array}$ & $\begin{array}{c}\boldsymbol{\sigma}_{\mathbf{2}} \\
(\mathbf{N} / \mathbf{m} 2)\end{array}$ \\
\hline $\begin{array}{c}\text { One } \\
\text { side } \\
\text { load }\end{array}$ & $\begin{array}{c}216.16 \\
\times 10^{-6}\end{array}$ & 1095.4 & 1758.3 & $\begin{array}{c}5.07 \\
\times 10^{6}\end{array}$ & $\begin{array}{c}8.134 \\
\times 10^{6}\end{array}$ \\
\hline $\begin{array}{c}\text { Uniform } \\
\text { load }\end{array}$ & $\begin{array}{c}216.16 \\
\times 10^{-6}\end{array}$ & 574.4 & 574.4 & $\begin{array}{c}2.66 \\
\times 10^{6}\end{array}$ & $\begin{array}{c}2.66 \\
\times 10^{6}\end{array}$ \\
\hline
\end{tabular}

This shows that in case 1 , the force arrangement is dislocated at force angles during moving process. To overcome this, we have re-determinated the focus for these bars to place appropriately the force nodes and the connection position and reduce the force difference as well. The bars 1 and 2 bearing maximum load in this case satisfy the durable condition. Therefore, steel connection of mini lifting equipment is durable enough in the case of dynamic load or shift to a corner.

In the case of people and things in the middle of the upper frame, the load distributes equally for 4 angles.

$$
N_{A}=N_{B}=N_{C}=N_{D}=\frac{1800}{4}=450(N)
$$

Equilibrium equation at nodes: - with $\mathrm{N}_{\mathrm{A}}=\mathrm{N}_{\mathrm{B}}=450 \mathrm{~N}, \alpha=$ $51^{0}$. 
We have: N"'3 $=$ N'2 $=575.4 \mathrm{~N}, \mathrm{~N}$ '3 $3=\mathrm{N}$ '1 $=575.4 \mathrm{~N}$ and $\mathrm{N} " 4=\mathrm{N} 5=\mathrm{N} " 5=575.4 \mathrm{~N}$. Check the durability of the bars. The bars 3, 4 have a reaction force of N" $4=\mathrm{N}^{\prime \prime} 5=$ $575.4 \mathrm{~N}$, so the stresses present in the bars are the same as bars 1 and 2, and both satisfy the durable conditions as Figure 8.

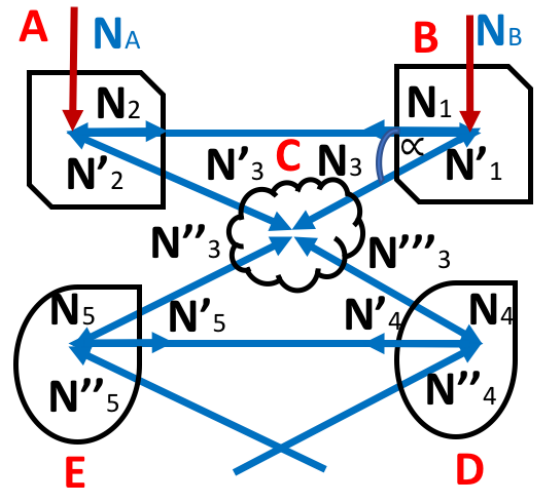

Fig. 8. Force distribution diagram in the case of uniform load

The results all load cases of mini lifting equipment are provided in Figure 9. When the bars in the mini lifting equipment are compressed at the center, the compressive stress calculated in the bar is much smaller than the critical compressive one. In the case where the load is deflected at an angle, and also bearded the dynamic load, the stress value on the bars is $8.134 \times 10^{6} \mathrm{~N} / \mathrm{m}^{2}$, corresponding to $1 / 17$ times the allowable stress; this value is reduced to $1 / 52$ in case of uniformly distributed load, i.e. in the middle of the upper frame of mini lifting equipment. Therefore, in all cases of work, the mini lifting device ensures durability and, based on this result, the lifting capacity of the lifting device can be increased to a larger value.

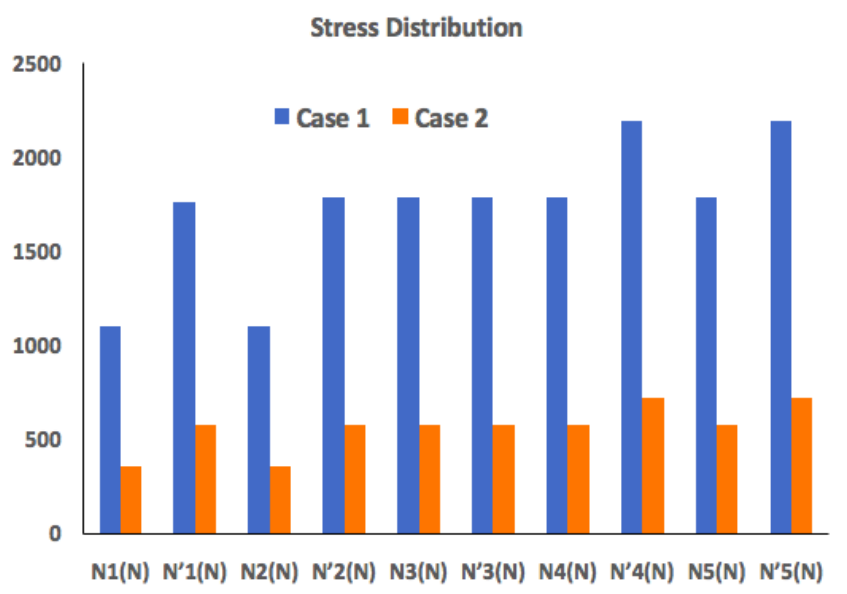

Fig. 9. Results of stress distribution at the linked points

\section{DIFFERENT OF STRESS THREE METHODS}

Figure 10 shows the different of stress between three methods: separation of nodes, finite element analysis method and ADAMS/View. In Case 1, where people and things are nearest to the corner, the stress in bar 1 are similar with 8.13 $\mathrm{MPa}, 8.22 \mathrm{MPa}$ and $8.2 \mathrm{MPa}$, respectively and the stress difference is about $0.86 \%$. In contrast, the stress in bar 2 are approximately $5 \mathrm{MPa}$, smaller than that in bar 1 . In Case 2 of people and things in the middle of the upper frame, the highest stress in bar 1 and bar 2 is $3.15 \mathrm{MPa}$, and the stress difference of bar 1 and bar 2 are similar at $1.91 \%$. The stress in bar 1 and bar 2 in two cases are significantly smaller than limited stress.

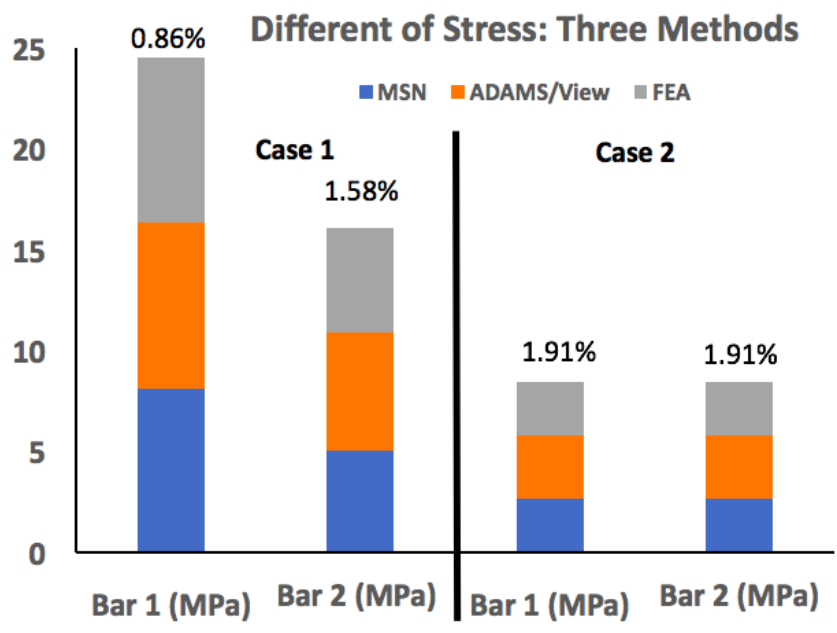

Fig. 10. The different result between MSN, ADAMS and FEA

\section{CONCLUSIONS}

We have used three methods of analysis by simulation, calculation, and evaluation of stresses at link positions of mini lifting equipment. The results are shown clearly in all three methods at binding areas with a permissible load of 150 $\mathrm{kg}$ during simulation and analysis. By using compression stress and the method of separations of nodes in the case of dynamic loads and static loads, we can see that this method could allow for possible extension in the next study to build the stiffness matrix described as a program for computers. The other two methods using CAD software can find differences in the allowable stress distribution by meshing and force arrangement to demonstrate that the lifting equipment is safe with the load $150 \mathrm{~kg}$. This article also performs force analysis with Adams/view software and the stress differences between three methods: separation of nodes, finite element analysis method and ADAMS/View.

\section{ACKNOWLEDGMENT}

This research is funded by Funds for Science and Technology Development of the University of Danang under project number B2017-ĐN06-08.

\section{REFERENCES}

[1] R. Dong, C. Pan, J. Hartsell, D. Welcome, T. Lutz, A. Brumfield, J. Harris, J. Wu, B. Wimer, V. Mucino and K. Means, "An Investigation on the Dynamic Stability of Scissor Lift," Open Journal of Safety Science and Technology, Vol. 2 No. 1, 2012, pp. 8-15. doi: 10.4236/ojsst.2012.21002.

[2] M. J. Burkart, M. McCann and D. M. Paine. Aerial Work Platforms, in Elevated Work Platforms and Scaf-folding. McGraw-Hill, New York, (2004). 
[3] M. T. Islam, C. Yin, S. Jian and L. Rolland, "Dynamic analysis of Scissor Lift mechanism through bond graph modeling," 2014 IEEE/ASME International Conference on Advanced Intelligent Mechatronics, Besacon, 2014, pp. 1393-1399. doi: 10.1109/AIM.2014.6878277.

[4] M, Kumaresan \& , Senthil. (2015). Design and Kinematic Analysis Of Gear Powered Scissor Lift. International Engineering Research Journal. 1. 1263-1266.

[5] В.Г.Ананин, С.Нураков, В.С.Калиниченко, А. Б. Калиев. Определение оптимальных параметров металлоконструкции подъёмника сопряженно-рычажного типа, (2011).

[6] C. S. Pan, A. Hoskin, M. McCann, D. Castillo, M. Lin and K. Fern, "Aerial Lift Fall Injuries: A surveillance and Evaluation Approach for Targeting Prevention Activities," Journal of Safety Research, Vol. 38, No. 6, 2007, pp. 617-625. Hdoi:10.1016/j.jsr.2007.08.002

[7] S. Tamate, N. Suemasa and T. Katada, "Analyses of Instability in Mobile Cranes Due to Ground Penetration by Outriggers," Journal of Construction Engineering and Management, Vol. 131, No. 6, 2005, pp. 698-704. Hdoi:10.1061/(ASCE)0733-9364(2005)131:6(689).
[8] http://hamachiglobal.com.vn/

[9] Nguyen Thi Hai Van, Nguyen Le Van, Nguyen Thai Duong, "Force and stress analysis at the linkage points of the mini lifting device by adams/view and inventor software", the 4th national scientific conference on applying new technology in green buldings (the 4th atigb 2018).

[10] S. Mingzhou, G. Qiang and G. Bing. Finite element analysis of steel members under cyclic loading. Finite Elements in Analysis and Design, 39 (1), (2002), pp. 43-54.

[11] J. Kim, M.J. Pratt, R.G. Iyer, and R.D Sriram. Standardized Data Exchange of CAD Models with Design Intent. Computer-Aided Design, 40 (7), (2008), pp.760-777.

[12] “ADAMS Guide," 2007 Version, MSC Software Incorporated, Ann Arbor, USA.

[13] San Luis Obispo, "design and analysis of a lift assist walker", Master Thesis of Science in Mechanical Engineering, Faculty of California Polytechnic State University, 2016. 